\title{
The Critical Role of Leadership in the New Zealand State Sector
}

\author{
Kerry McDonald
}

\section{Introduction}

If New Zealand is to be able to arrest its steadily deteriorating economic performance and position compared with many other countries, particularly Australia, one thing it must do urgently is to radically improve the quality of leadership and performance within its central government agencies. Substantial economic and social benefits will flow from such remedial action, but high costs will be paid if it is not taken.

There are major weaknesses in capability and performance in the New Zealand public sector, particularly in the public service. They reflect the lack of an integrated, coordinated and strategic, 'whole of government' approach to important social and economic issues; a failure to address a number of clear and serious systems deficiencies; a willingness to accept poor performance and results, in spite of the adverse impact on New Zealand's economic performance and living standards; and insufficient openness and transparency in regard to the sector's performance and results.

These weaknesses are evident in inconsistent and sometimes manifestly inadequate leadership in the sector; a lack of attention to important organisation and systems issues; poor policy design and implementation and weak administrative and operational performance; unacceptable and costly performance failures; and, ultimately, poor results - especially in terms of the economy, social outcomes and living standards generally. The poor results seem to have led to less open and informative performance monitoring and communication.

There are many capable people and good organisations in the public sector, performing to a good - sometimes excellent - standard. It is unfair to them, and all New Zealand citizens, that the major and systematic weaknesses have not been and are not being addressed. They have been clearly evident for some years now.

\section{The wider context}

There has been a continuing failure of New Zealand's leaders and policies to deal with the continuing deterioration in New Zealand's economic performance and standards of living compared with Australia and many other economies. At the same time there has been a sharp increase in the competitive and other pressures facing New Zealand - e.g. China, India, international tax reform, sustainability, Australia's policies and performance, new international business strategies, biosecurity, trade negotiations and climate change - and our responses to these pressures have generally been piecemeal and limited. There has been insufficient attention paid to important economic and social objectives. Between 1960 and 1999 New Zealand's growth in exports per capita was less than half ( $45 \%$ ) of Australia's, and only $41 \%$ of the OECD average rate of increase. Over the same period New Zealand's productivity growth performance was worse - only $40 \%$ of Australia's and $25 \%$ of the OECD average. Then, between 2000 and 2005, New Zealand's productivity trend growth rate declined to only half the trend growth rate between 1992 and 2000 , from $2.5 \%$ per annum to $1.1 \%$ per annum. From 1999 to 2006, Australia's exports per capita increased $66 \%$ and New Zealand's by only 36\%. Information recently available from Statistics New Zealand suggests that productivity growth in the 'market' sector may have been in line with Australia's in recent years, which means that in the 'non-market' sector, of which the public sector is a major part, productivity performance has been very poor. A recent study (Rennie, 2007) supports that view and argues that, based on an analysis of a range of social indicators, the massive increase in government spending in recent years, some $\$ 20$ billion, has not produced better outcomes. 
As exports per capita and productivity are critical determinants of living standards, these trends are particularly serious. It must also be noted that New Zealand's current account deficit at over 9\% of GDP is amongst the largest in the OECD, and is about twice what might be sustainable. In addition, New Zealand's net international investment position is one of the worst amongst developed economies. It continues to deteriorate, weakening the current account outlook. Better growth rates in several recent years primarily reflected abnormally high and unsustainable increases in terms of trade, net immigration and labour participation. New Zealand's capital:labour ratio, $95 \%$ of Australia's in the late 1970 s, is now only some $70 \%$, which has serious implications for future relative productivity improvement and incomes. Australia's recent superannuation changes highlight New Zealand's relatively weak policy settings and performance.

Clearly, it is essential that New Zealand lifts its game - but where does the public sector sit in all of this?

\section{Serious shortcomings}

The post-1987 major reforms in the New Zealand public sector were fundamental and pervasive. They had a very substantial positive impact through the development of a more efficient, effective, resultsoriented and accountable public sector. The more decentralised and targeted approach allowed greater scope for capable leaders and managers to innovate and improve performance. Inevitably, there were aspects that have required reworking, as well as unfinished business, but the benefits of the reforms were clearly very substantial.

However, since the major reforms there has been little further progress, and in some respects things have gone backwards. In its report on state sector organisations, including the public service, the State Sector Standards Board (SSSB) (2002) highlighted areas of significant concern which continued to require serious attention. These included:

- quality of leadership;

- quality and effective use of performance management systems;

- inadequate attention to training and development of staff;
- lack of focus on succession planning and career development;

- the need for a remuneration strategy;

- orientation to 'whole of government' approaches;

- emphasis on outputs at the expense of outcomes.

Four years on there is no evidence of significant, sectorwide initiatives or improvement. A Treasury report on aspects of public service performance (reported in the National Business Review, 19 March 2004) concluded that 'Managing for Outcomes' is part of a strongly worded State Services Commission (SSC) aspiration to improve the effectiveness of government expenditure. However, it observed that departments and agencies have managed to avoid many of the more onerous aspects of the new regime, according to an evaluation of the content and quality of the statements of intent prepared in the last financial year. In the words of the report, 'Departmental capacity to undertake meaningful organisational capability appraisal appears limited. Departments do not have a clear picture of their current state or future capability requirements, or access to common capability appraisal metrics'. It was also noted that outcome indicators of performance measures are virtually non-existent in the majority of 2003/04 statements of intent; that the identification of risk and risk management was very limited; that departments tend to assert linkages to each others' outcome sets, rather than describe how collaboration or shared outcome contributions will work; and that interdepartmental collaboration occurs despite the system, not because of it. Where real collaboration does happen, it does so only because determined professionals on the ground make it happen.

Organisational capability is a critical issue. It is a major determinant of what can be achieved, to what standard and at what cost. Improving it is a vital part of overall performance improvement. Yet departmental capacity to undertake meaningful organisational capability appraisal appears limited, and agencies do not have a clear picture of the current state of their organisation or of future capability requirements, or access to common capability appraisal metrics. For example, a recent report on the current state of the Ministry of Health (2006), one of the New Zealand public sector's largest organisations, with a critical role in terms of the living standards of New Zealanders, found that the ministry has no strategic 
plan and that there is none for the health sector; that it is oriented to process tasks, not key priorities and objectives; that it has an inward-looking, directorateoriented, silo approach; that it lacks key performance indicators to enable measurement of progress; that it has weak performance management and orientation to plan targets; and that it has a risk-averse culture with slow and reactive decision making. I also note a Treasury report (see New Zealand Herald, 16 February 2007) which states that there was an $8 \%$ fall in hospital productivity between 2001 and 2004, compared to a 1\% increase in the previous three years. Treasury also found that only $25 \%$ of the activities carried out by New Zealand's 21 district health boards were actually measurable!

Obviously, these are serious weaknesses, and especially remarkable since the Ministry of Health is not a new organisation, its previous chief executive was in the role for a number of years, and New Zealand now has a third-term government which has put considerable focus on the health sector.

In my judgement, two initial conclusions can be drawn. First, there are serious weaknesses in the capability and/or willingness of some public sector leaders - both officials and ministers - to actually lead and manage their responsibilities and organisations. Secondly, important sector-wide systems and processes - e.g. planning and goal setting, performance monitoring and management, staff training and development, performance improvement, consequence management, and the related central leadership and oversight - are inadequate in both their design and operation.

The root cause of this situation seems to be a lack of leadership, capability and commitment in addressing these important issues, exacerbated by aversion to change and the risks involved, and a willingness to accept, even to prefer, weak or poor performance rather than risk change. The absence of a decisive political constituency for improvement is also relevant. This reflects, at least in part, the lack of openness and transparency on good performance indicators, although the frequent incidents of performance failure reported in the news media are a strong, albeit informal, indicator of performance.

Where progress is being made it is generally being led by individual chief executives, using their own initiative and sometimes with support or encouragement from ministers. Where leadership is capable, improvement is evident, and performance reflects this; and these improvements highlight what could be achieved on a sector-wide basis. As Graham Scott (2001, p.xxii) has commented:

the best public management in New Zealand is demonstrably as good as it gets anywhere in the world. There are, however, numerous innovations that have begun with great promise, but that have not been followed through and some lie neglected. We have talked incessantly about some problems but left them unsolved, such as the identification and development of top managers.

\section{Delegation and performance}

A key feature of the 1980s-90s reforms was the increase in the authority delegated to chief executives, especially in the public service. There were also major changes in the wider state sector, where the role of boards and directors became more significant, and often successful. This created the opportunity for capable chief executives to lead and improve the performance of their organisations.

Unfortunately, the key supporting systems for ensuring that the benefits were gained consistently on a sectorwide basis were not developed or implemented, or were done so on a limited and ineffective basis. That essentially remains the current position, and the absence of an effective systematic approach, particularly in the public service, to managing and improving performance is a fundamental and costly weakness.

It is notable that this has been the situation for quite a few years now and that the problem is widely recognised, but decisive steps have not been taken to remedy the position. That sends a signal about New Zealand's approach to public sector performance - that good performance and performance improvement are not priorities for the sector's leadership.

Why is a systematic sector-wide approach so important?

\section{Leadership}

Capable leadership, in all its forms, is less about style and personality, though this has some relevance, and much more about learned techniques and methods and experience. Importantly, the required leadership 
capability is different from role to role and between levels in any organisation. A good organisation has the requisite, capable leadership at all levels.

The leader of an organisation, e.g. a public service chief executive, must be able to lead that organisation - to think strategically, set goals and objectives, develop a team, manage performance, achieve outcomes, plan and so on. A key part of the role capability is 'organisational leadership': the knowledge, skills and experience to develop and improve the capability of the organisation to perform, to work on the organisation and not just in it. Ministers, at a different level and with a different role, need other forms of leadership capability in guiding and overseeing chief executives and their performance.

Leadership capability varies considerably amongst public sector executives and amongst ministers, as it can do in any organisation. Some are experienced, talented and capable and others are less so. The variation is not surprising and partly reflects experience, including exposure to good training and development - and to good leadership. This variation in capability is clearly evident in the variation in performance amongst public sector organisations. Some perform well, others less so, and some clearly struggle.

The steps taken to improve the standard and consistency of public sector leadership have been very small, in relation to the size and significance of the issue, and there are still no effective, sector-wide systems or processes to achieve the required outcomes.

There is similar variation in the leadership capability of ministers, who are selected through a political process. Most come from backgrounds that gave little or no exposure to the requisite leadership skills for their present role, which include organisational leadership and guiding struggling chief executives on their performance and on organisational development. Short, well-focused workshops for ministers, to outline, inform and remind, could be very productive, but the SSSB's recommendation on this was not taken up.

A more substantial and systematic approach to developing consistent high capability amongst public sector leaders would improve the sector's performance markedly. In organisational terms this would simply be reducing or removing unwanted variance in performance - a classic case for Six Sigma methodology. There is a leadership development programme presently in place, but it is too limited to be effective.

The problems caused by the variability of leadership partly reflect and are compounded by the weak approach to performance management, particularly in the public service.

\section{Performance management}

Good performance management is critical for any organisation. It needs to be based on an agreed role description and performance objectives. It must entail regular formal review meetings (at least two per year) with a manager who is experienced and capable, and at the organisation level of the person whose performance is being reviewed, or preferably higher. It must assess performance fairly and frankly against the agreed criteria, reaching an agreed outcome, or with a process to resolve differences.

The outcome must lead to good performance being rewarded and poor performance being appropriately sanctioned. The outcomes should include an agreed training and development programme. Where there are serious performance problems there must be personal counselling and an agreed development plan, which leads to sufficient improvement or exit from the role. The formal meetings should be complemented by regular informal meetings.

There is a performance management system in the public service, but it is-ineffective in managing the performance of public service senior executives. This is evidenced by the poor performance of some individuals and organisations, over sustained periods, including the acceptance of poor performers continuing in their roles and the reappointment of some to new senior roles. The system is more akin to a plan review, based on data collection and analysis, than a personal performance review. The reviewers generally lack the experience in sufficiently senior roles that would have allowed them to develop the necessary judgement and other skills needed to effectively review a chief executive's performance. It is also questionable whether they have the required technical skills and knowledge for the role.

Properly reviewing a person's performance is a difficult and demanding task, and unless it is done to a high standard the results will be poor, to the detriment of the employee, the organisation, the sector and policy 
outcomes. The results will also lack the robustness and credibility needed to support serious consequences for failure to perform, given the present legal framework. This is probably another reason for ongoing poor performances.

These problems with performance management also appear to be present within organisations as well, not just with chief executives, limiting the ability of organisations to improve their performance.

Many public sector employees regard performance management negatively, as a disciplinary tool rather than as a positive input into their capabilities and career development. Thus, although the public service operates on the basis of delegated authority, it lacks the complementary systems necessary to operate efficiently and effectively in this way.

\section{'Whole of government' outcomes}

There has been an inadequate emphasis on and progress towards 'whole of government' outcomes, even though this has been a stated priority for some years. In a good organisation, which comprises a number of divisions, each of these is led by a manager with delegated authority from the centre. Each manager will be judged on the basis of his/her divisional result, and the impact of their work on the whole organisation. For example, a new group-wide IT system may be proposed. It may be advocated as being in the best interests of the whole, but often divisional managers will have discretion as to whether to adopt or not, as in the public sector. If opting out of the group solution turns out to be a bad decision their performance will be marked down accordingly.

However, in the public sector there is little evidence of any consequences from a failure to act beyond a narrow interest, and a great reluctance to mandate 'whole of government' or best practice solutions. And the negotiation of them is generally a slow, difficult and inefficient process. This is a major issue for the sector as it also frustrates the transfer, development and adoption of good/best practice, access to scale economies, common approaches to IT and other systems, and the achievement of a credible, 'whole of government' approach.

\section{Organisational development}

Organisation development and performance is a key area for leadership accountability, but it is an area of particular weakness in the public sector. Some organisations are making progress but many are not, because they are not alert to the significance of the issue, particularly when the leader lacks the relevant knowledge and experience. In such circumstances the absence of a systematic, sector-wide framework has serious consequences.

Organisation development is important because it improves the design of an organisation and its ability to achieve its purpose effectively and efficiently. It starts with basic issues such as what roles should be established, at what level in the organisation, then includes the systems and processes that link roles, including the setting of tasks and the management of performance.

Organisations are typically hierarchical, with the more complex and difficult work being done at higher levels in the organisation. Basically, the middle and lower levels operate the business within the existing organisation, systems and processes, while the higher-level roles should be primarily focused on improving the organisation and its performance.

Without a well-designed performance management system, properly applied, it is common for senior executives to 'dip down' and focus excessively on the work and performance of the subordinates, rather than on the typically more difficult but vital improvement work that their role description requires. This is a widespread failing, one which means that the subordinates are frustrated by excessive supervision and oversight and the important work of the more senior roles is not completed. This is a classic recipe for organisational weakness and performance failure.

In contrast, an effective process of organisational development will increase the amount of work that is delegated to the lower levels of the organisation, giving these employees more discretion and opportunity to exercise judgement and to perform to a higher level, together with the requisite training. Typically, in an organisation that is performing at a high standard much more work is being undertaken at the lower levels of the organisation, because those employees have developed the capability and been given the opportunity. This is a virtuous-circle process because as lower-level employees develop increased capability and leadership skills they typically become more engaged with the business and, given the opportunity to contribute their ideas, often 
become a powerful force in improving performance. They know much more about what goes on at the bottom of the business, which is typically the key operational/service delivery/customer-facing area. This process is not only good for the organisation but also good for its employees, whose roles are enriched and capability enhanced. As more work is done at the lower levels of the organisation there is greater opportunity at higher levels to focus more intensively on organisational improvement.

The state sector would benefit very considerably from this sort of development, but without capable organisation leadership and guidance from the centre it is unlikely to happen.

\section{Policy capability}

There are now grounds for concern about the New Zealand public sector's policy capability. There seem to be numerous examples of policies that have been poorly designed and implemented in recent years, and much ineffective administration. These failings attract substantial coverage in the daily and business news media and in question time in Parliament; they are costly to immediate stakeholders; and they can cause serious frustration in the wider community.

The lack of ready access to meaningful and reliable performance indicators exacerbates the position, as does the perception of expenditure increases not matched by better outcomes (e.g. in health, education and welfare). Political and official public comment often seems more oriented to denying weakness or failure than to frankness. And many officials now seem increasingly reluctant to engage in and inform public debate on policy and other issues.

An important related issue is the absence of any real sense or evidence of a sound strategic policy framework, for either social or economic policy. There are political agendas, but nothing reflecting quality analysis, oriented to national objectives.

Two examples are illustrative. The Kyoto treaty ratification was a contentious political choice. Ratification was justified with a clear statement of what the implications would be for New Zealand, including the expectation of substantial economic benefits. The subsequent policy design and consultation process had some good features, but it quickly became clear that the political framework for the policy was rather speculative and that the policy process lacked the capability to deal with the relevant, complex economic, scientific and social issues. Not only was this disconcerting for those who collaborated with the process, but involvement in it became an increasingly risky and costly exercise. The ultimate result, after the policy had been implemented, was its collapse, as analysis errors and other problems emerged. Yet this policy has major implications for important elements of the New Zealand economy, such as agriculture, fishing, forestry, mining, manufacturing, transport, and for the exports that the country is so dependent on.

The electricity policy position is broadly similar. Since the mid-1980s energy policy development has been contentious and often ill-founded. The focus has typically been on the interests of the suppliers rather than the users, with the allocation of risk biased against users. There has been no obligation to supply, a lack of clarity about supply-side obligations and considerable opportunity for the supply side to game or otherwise exploit the market. A real problem has been that the policy makers appear to have lacked understanding of the issues and their significance, and the capability to develop sound policy. There is now less confidence amongst energy users that policy will take reasonable account of their interests and their significance for the New Zealand economy, in competition with more political objectives such as sustainability and the need to be active on climate change. The latter are important, but there needs to be a rigorous and balanced assessment of policy options, their economic, social and environmental impact, and sound policy design.

Sustainability is a key issue for New Zealand, but the greatest threat to New Zealand's sustainability is its poor and still deteriorating economic performance, with its adverse impact on living standards and the capability to manage and conserve the environment and address the country's social and international obligations.

The current state of the forestry sector reflects these sorts of policy problems. New Zealand has a large investment in exotic forests, but it is difficult to see how this will be realised, given the major investments in plant and infrastructure, and the economic energy supply needed for the value-adding processing that is essential to get an economic return on the forests. The uncertain policy environment for such investment is a serious problem. 
Another feature of the current policy process is the reduced public engagement by officials in constructive and informative ways, such as outlining options and debating solutions. Nor do officials now seem obliged to give 'free and frank' advice to ministers, which has been one of the foundations of our Westminster-style democracy.

\section{Why is public sector performance not a top priority?}

There is so little focus on and concern with public sector performance because not many people understand the issues; and because there is little voter interest in the subject - except when something goes badly and publicly wrong - the political incentive to change is not strong. The added cost to business and detriment to the economy and the New Zealand community from poor public sector performance are only narrowly understood and generally not recognised as being important, particularly as the costs are typically intangible, diffuse and remote from most individuals.

For these reasons the development of in-house leadership capacity and commitment is probably the only real answer.

\section{Conclusion: what is to be done?}

New Zealand faces the challenge of being a small and relatively remote economy in a world in which most other countries are growing faster, are more competitive where it counts, and are outstripping New Zealand in terms of living standards. It is also a world of increasing risks which need to be astutely assessed and responded to, such as climate change, conflict, environmental capacity and so on.

The country cannot afford to have those difficulties compounded by poor policy design, implementation and operation and an inefficient public sector. These problems not only erode the living standards of New Zealanders but they also undermine New Zealand's credibility internationally and its capacity to engage credibly and effectively with other nations. In particular, its relative economic decline compared with Australia, which shows no sign of reversing, will have increasingly significant consequences for that relationship.

Decisive action needs to be taken, particularly by government leaders. The focus needs to be on sound policy, oriented to longer term objectives and not shortterm political objectives. Business is, typically, getting on with business, in the interests of shareholders and other stakeholders, but there is some reluctance to invest in New Zealand. The policy and tax environment, the policy risk and attitude to business and the economic outlook are all significant negative influences. At the Big End of Town there has been a real hollowing out, including a downgrading by multinationals of their presence in New Zealand, which has serious consequences.

The public sector is part of the problem, for the reasons outlined above, but it should, and must, be a key part of the solution. Business has the discipline of markets, but the public sector generally does not. It does, however, have the advantage of a single, dominant and powerful owner and an integrated structure. Most of the present problems reflect an unwillingness, or inability, to use this structure effectively.

There must be decisive action because the consequences of the ongoing relative decline, particularly compared to Australia, are becoming increasingly serious. To this end I recommend an urgent review of the SSC's performance management system and processes. This should be carried out by a small expert working group, focusing on their effectiveness and potential for improvement, with preliminary results reported within three months. This group should recommend what further work needs to be done to make the necessary changes, with a view to beginning implementation within 12 months.

In addition, there should be a more comprehensive review of the public sector, focusing on its institutions, policies, systems and processes, and particularly its effectiveness and efficiency, identifying weaknesses and what needs to be changed if the sector is to realise its potential. This review should be conducted by an independently led group comprising appropriate expertise, with a majority membership from outside the sector. It should report within 12 months, with the aim of changing policies within 18 months. The key areas demanding the attention of such a group would be: the role and performance of the SSC and central agencies, particularly in relation to performance improvement and ensuring better outcomes; the quality of public service leadership and how to improve and sustain it; the whole area of employee development and succession planning; the achievement of more consistent, higher performance 
standards across the sector, including how to implement best practice and beneficial common solutions and a more effective orientation to 'whole of government' outcomes; improving the planning and reporting process, making it more effective and meaningful, including introducing a public reporting system based on meaningful key performance indicators; ministerial interaction with the public sector, especially with chief executives, and how to improve the effectiveness of these relationships; and how an efficient public sector should work.

\section{References}

Ministry of Health (2006) Review of the Current State of the Ministry of Health, as at 13 December 2006, Wellington: Ministry of Health

Rennie, P. (2007) New Zealand's Spending Binge, St Leonards, NSW: The Centre for Independent Studies, 15 March

Scott, G. (2001) Public Sector Management in New Zealand: lessons and challenges, Canberra: Centre for Law and Economics, Australian National University

State Sector Standards Board (2002) The Ethos of the State Sector: report to the minister of state services, 30 June 2002, Wellington: State Services Commission

Kerry McDonald is Chairman of the Bank of New Zealand, and a full-time company director. He is a former director of the New Zealand Institute of Economic Research, and a former chief executive of Comalco (NZ) Ltd. $\mathrm{He}$ has been closely involved in the theory and practice of developing high performance organisations. $\mathrm{He}$ chaired a governmental committee which oversaw the restructuring of the Department of Conservation after the Cave Creek tragedy, was chairman of the State Sector Standards Board in the early 2000s, and has been a member of several government advisory and other groups.

\section{MAKING ENERGY WORK:} A sustainable energy future for New Zealand

\section{An Institute of Policy Studies publication written by Christina Hood and Colin James}

Energy is at the core of modern life and the supply and cost of it is of great importance, not just to remote policy makers in Wellington but to all of us in our everyday life. This short book examines how New Zealand can increase its energy sustainability - both in the sense of ensuring adequate energy to meet economic and social needs, and in the sense of energy that is environmentally sustainable.

Christina Hood and Colin James draw on the wide range of expertise brought together in 2006 when the Institute of Policy Studies held a series of roundtable discussions on energy sustainability. These discussions involved about 60 of New Zealand's leading energy specialists and stakeholders, as well as overseas experts. This volume reflects the themes and issues discussed at these meetings.

Published - March 2007

Format - A5 Paperback, pp 94

ISBN - 1-877347-17-5

Price - \$25.00 (including P\&P within New Zealand)

To have a copy of Making Energy Work and an invoice sent to you, please email, phone, fax or mail your order to:

\section{Institute of Policy Studies}

Victoria University of Wellington

Email ipos@vuw.ac.nz

Telephone +64 44635307

Fax +64 44637413

P0 Box 600, Wellington

New Zealand 